University of Nebraska - Lincoln

DigitalCommons@University of Nebraska - Lincoln

Faculty Publications: Department of Entomology

February 2003

\title{
Inheritance of Methyl-parathion Resistance in Nebraska Western Corn Rootworm Populations (Coleoptera: Chrysomelidae)
}

\author{
Srivinas Parimi \\ University of Nebraska-Lincoln \\ Michael E. Scharf \\ University of Nebraska-Lincoln \\ Lance J. Meinke \\ University of Nebraska-Lincoln, Imeinke1@unl.edu \\ Laurence D. Chandler \\ University of Nebraska-Lincoln \\ Blair D. Siegfried \\ University of Nebraska-Lincoln, bsiegfried1@ufl.edu
}

Follow this and additional works at: https://digitalcommons.unl.edu/entomologyfacpub

Part of the Entomology Commons

Parimi, Srivinas; Scharf, Michael E.; Meinke, Lance J.; Chandler, Laurence D.; and Siegfried, Blair D., "Inheritance of Methyl-parathion Resistance in Nebraska Western Corn Rootworm Populations (Coleoptera: Chrysomelidae)" (2003). Faculty Publications: Department of Entomology. 42.

https://digitalcommons.unl.edu/entomologyfacpub/42

This Article is brought to you for free and open access by the Entomology, Department of at DigitalCommons@University of Nebraska - Lincoln. It has been accepted for inclusion in Faculty Publications: Department of Entomology by an authorized administrator of DigitalCommons@University of Nebraska - Lincoln. 


\section{Inheritance of Methyl-parathion Resistance in Nebraska Western Corn Rootworm Populations (Coleoptera: Chrysomelidae)}

Srinivas Parimi, Michael E. Scharf, Lance J. Meinke, Laurence D. Chandler, and Blair D. Siegfried

Journal of Economic Entomology

Volume 96, Issue 1 (February 2003) pp. 131-136

DOI: 10.1603/0022-0493(2003)096[0131:IOMPRI]2.0.CO;2

Authors may post electronic reprints of their own journal articles after an embargo period of two years has passed from the date of publication. Also, authors must include on the electronic reprint the following statement:

This article is the copyright property of the Entomological Society of America and may not be used for any commercial or other private purpose without specific written permission of the Entomological Society of America. 


\title{
Inheritance of Methyl-parathion Resistance in Nebraska Western Corn Rootworm Populations (Coleoptera: Chrysomelidae)
}

\author{
SRINIVAS PARIMI, MICHAEL E. SCHARF,${ }^{1}$ LANCE J. MEINKE, LAURENCE D. CHANDLER ${ }^{2}$ AND \\ BLAIR D. SIEGFRIED ${ }^{3}$
}

Department of Entomology, 202 Plant Industry Bldg., University of Nebraska-Lincoln, Lincoln, NE 68583-0816.

J. Econ. Entomol. 96(1): 131-136 (2003)

\begin{abstract}
Field populations of western corn rootworm, Diabrotica virgifera virgifera LeConte, were collected from three different sites (York Co., Phelps Co., and Saunders Co.) in Nebraska during 1996. Adult bioassays of these three populations were conducted with different concentrations of methyl-parathion and at a diagnostic concentration $(1.0 \mu \mathrm{g} / \mathrm{ml})$ to determine resistance levels among these populations. Self and reciprocal crosses were made between the two resistant and one susceptible laboratory-reared populations. Dose-responses and dominance ratios calculated for the four reciprocal crosses indicated that resistance was incompletely dominant in both strains, although in one of the strains there was an indication of sex linkage. However, evaluation of native polyacrylamide gels stained for nonspecific esterases and nonspecific esterase activity of parents and $F_{1}$ progeny of the crosses suggested that esterase inheritance was completely dominant and autosomal. The results of this study were inconclusive with regard to the precise nature of inheritance, because the bioassays and esterase assays could not discriminate between heterozygotes and homozygotes. However, they do provide insight into the potential for developing simple diagnostic assays to assess resistance frequencies. Based on the inheritance studies described in this investigation, we can begin to generate information on specific genetic factors that dictate the evolutionary divergence of discrete resistant populations and facilitate modeling efforts designed to approximate the movement of genes for resistance among populations.
\end{abstract}

KEY WORDS western corn rootworm, Diabrotica, esterase, inheritance, reciprocal cross

THE WESTERN CORN ROOTWORM, Diabrotica virgifera virgifera LeConte, is the most significant economic pest of field corn, Zea mays L., in the United States. Larval injury to corn roots may disrupt plant water relationships (Riedell 1990, Hou et al. 1997), increase susceptibility to lodging (Sutter et al. 1990, Spike and Tollefson 1991), and reduce grain yield (Godfrey et al. 1993, Gray and Steffey 1998, Urías-López and Meinke 2001). Insecticides are often applied to nonrotated corn to manage corn rootworm populations. One approach is to apply a soil insecticide at planting or first cultivation to control larvae in the root zone (Mayo and Peters 1978). An alternative strategy is to use a foliar insecticide to suppress adult rootworms and reduce egg laying so that larval populations will not cause economic loss the following season (Pruess et al. 1974).

Recently, we have documented that populations of adult western corn rootworms in Nebraska have become resistant to methyl-parathion and carbaryl insecticides (Meinke et al. 1998) resulting in field re-

\footnotetext{
${ }^{1}$ Department of Entomology, Purdue University, West Lafayette, IN 47907-1158.

${ }^{2}$ Red River Valley Experiment Station, USDA-ARS, Fargo, ND 58105-5677.

${ }^{3}$ E-mail: bsiegfried1@unl.edu.
}

ports of insecticide failures. Resistance has been identified in areas in which adult management has been practiced over large geographic areas for multiple years in succession (Meinke 1995). The mechanisms of resistance involve the combined effects of hydrolytic and oxidative metabolic enzymes as well as target site insensitivity (Miota et al. 1998; Scharf et al. 1999, 2001), although elevated activity of hydrolytic enzymes (nonspecific esterases) has been shown to be common to all populations. Three groups (groups I, II, and III) of esterase isozymes have been identified in homogenates of western corn rootworm adults based on electrophoretic mobility, although only the group II isozymes exhibit elevated activity and are highly correlated with resistance levels among field populations (Zhou et al. 2002). Therefore, characterizing the inheritance of existing esterase-mediated resistance in areas of Nebraska in which adult management is common presents a unique and potentially finite window of opportunity to generate critical information with regard to resistance development and proliferation.

The investigation reported herein was conducted to determine the inheritance of resistance and elevated esterase activity among reciprocal crosses of organophosphate-resistant and -susceptible rootworm pop- 
ulations. Information generated from these studies will be important for understanding the response of rootworm populations to the selective pressures exerted by pest management tactics and the movement of resistance genes.

\section{Materials and Methods}

Reciprocal Crosses. Insecticide-resistant western corn rootworm field populations $(\approx 5,000$ individuals per site) were collected from three areas of Nebraska in 1996: Saunders Co. (susceptible), York Co. (resistant), and Phelps Co. (resistant). Reciprocal crosses were made in 1997 and 1998, with the laboratoryreared $F_{1}$ and $F_{2}$ populations, respectively, originating from 1996 collections. Teneral male-female pairs were placed in oviposition boxes modified from Boetel and Fuller (1997) using 15-20 pairs per cross in 1997 and 30 pairs in 1998. Oviposition boxes contained a substrate of moist autoclaved soil, and beetle pairs were provided a diet of sweet corn ears and fresh lettuce leaves. After females died, oviposition boxes containing soil and eggs were held at $23^{\circ} \mathrm{C}$ for 1 mo. Eggs were then separated from soil, counted, and placed on autoclaved wet soil. Eggs collected from each female parent were then stored separately in sealed Petri plates at $5^{\circ} \mathrm{C}$ for 6 mo before hatching at $23^{\circ} \mathrm{C}$. Progeny from individual females were reared separately in shoebox-sized plastic containers (up to 100 per container) that contained germinated corn seeds as a food source. Adults from individual crosses were pooled and maintained on sweet corn ears and fresh lettuce leaves for at least $5 \mathrm{~d}$ before use in bioassays or frozen at $-80^{\circ} \mathrm{C}$ for subsequent esterase activity assays.

Insecticide Bioassays. Bioassays were conducted in 1998 and 1999 within 20-ml glass scintillation vials treated with one of three methyl-parathion concentration ranges that produced between 1 and $100 \%$ mortality (homozygous susceptible range $=0.063-2.0$ $\mu \mathrm{g} / \mathrm{ml}$; heterozygous range $=0.195-6.25 \mu \mathrm{g} / \mathrm{ml}$; homozygous resistant range $=0.781-25.0 \mu \mathrm{g} / \mathrm{ml}$ ). The six insecticide dilutions in each concentration range were prepared as serial dilutions in acetone from technical grade methyl-parathion (Chem Services, West Chester, PA) of $>99 \%$ purity. Vials were treated with $0.5 \mathrm{ml}$ of insecticide dilution (or acetone alone for controls) and mechanically rolled until dry in a fume hood. For each population, 10 beetles (mixture of both sexes) were placed in each vial. One replicate was performed per day and bioassays were conducted over 5-7 d, depending on the availability of beetles. Bioassay vials containing beetles were held at $22^{\circ} \mathrm{C}$ in darkness for $4 \mathrm{~h}$, and then mortality was scored as a lack of any movement.

Bioassay data from 1998 and 1999 were pooled and analyzed by probit analysis (Finney 1971) using commercially available software (POLO PC, LeOra Software 1987). The significance of differences among slopes was determined by the likelihood ratio tests for parallelism, and significant differences among $\mathrm{LD}_{50}$ values were determined by the likelihood ratio test for equality with pair-wise comparisons determined by nonoverlapping confidence intervals (Savin et al. 1977). The degrees of dominance were calculated using methods described by Stone (1968) and Dittrich (1972).

Esterase Enzyme Preparation and Activity Assays. Adults obtained during 1999 were used for esterase activity assays and in native (nondenaturing) polyacrylamide gel electrophoresis (PAGE). Rootworm abdomens (one in each well) were placed into individual wells of a 96-well flat bottom microplate (353912 FALCON, Becton Dickinson Labware, Franklin Lakes, NJ) containing $100 \mu$ l ice-cold $0.2 \mathrm{M}$ sodium phosphate homogenization buffer ( $\mathrm{pH} 7.8$, $0.1 \%$ Triton X-100). Abdomens were homogenized by a combination of vertical and circular movements of a 96-spoke inoculating manifold (MC96, Dan-Kar, Reading, MA) for $30 \mathrm{~s}$. The homogenates from each beetle were then mixed and stored on ice for subsequent assays.

Abdomens of individual beetles were used as a protein source and $p$-nitrophenyl acetate (PNPA) was used as substrate for esterase activity assays. The homogenates $(10 \mu \mathrm{l})$ were transferred by a multichannel pipette to a new microplate and diluted 20 -fold with $0.02 \mathrm{M}$ sodium phosphate buffer ( $\mathrm{pH} 7.0$ ). Homogenates of 96 individual beetles (20-fold diluted) were transferred to a round-bottomed microtiter plate and $5 \mu \mathrm{l}$ of $10 \mathrm{mM}$ PNPA was added. The absorbance was read at $405 \mathrm{~nm}$ and used to quantify the esterase activity (nmol 4-nitrophenol/min/rootworm). An extinction coefficient of $6.53 \mathrm{mM}^{-1} \mathrm{~cm}^{-1}$ was used to convert the absorbance in $\mathrm{OD} / \mathrm{min}$ to nanomoles of nitrophenol produced over $2 \mathrm{~min}$. Data were analyzed using the PROC GLM procedure and means separated by least significance difference (LSD) test (SAS Institute 2001).

Esterase Native Polyacrylamide Gel Electrophoresis. Native (nondenaturing) PAGE was conducted on $8 \%$ resolving gels with $4 \%$ stacking gels and a discontinuous tris-glycine running buffer system. Volumes of abdominal homogenates were mixed with $1.5 \mu \mathrm{l}$ of loading buffer (tris-glycine running buffer containing $20 \%$ sucrose and $0.05 \%$ xylene cyanol) before loading onto the gels. Electrophoresis was conducted at $4{ }^{\circ} \mathrm{C}$ and $120 \mathrm{~V}$ before gels were removed and placed in 50 $\mathrm{ml}$ of $0.02 \mathrm{M}$ sodium phosphate buffer containing 0.5 $\mathrm{ml}$ of $20 \mathrm{mM} \beta$-naphthyl acetate in acetone. After 5 min, esterase bands were visualized by the addition of $1 \mathrm{ml}$ water containing $20 \mathrm{mg}$ fast blue BN (tetrazotized $O$-dianisidine).

\section{Results}

Insecticide Bioassays. Probit analysis results for pooled methyl-parathion bioassay data from the parental populations and their reciprocal crosses are presented in Fig. 1 and Table 1. The levels of resistance observed in the resistant parental populations were 5.2 and 7.9 at the $\mathrm{LC}_{50}$ for the York and Phelps populations, respectively. In both resistant populations, the slopes of the dose-response curves were significantly 

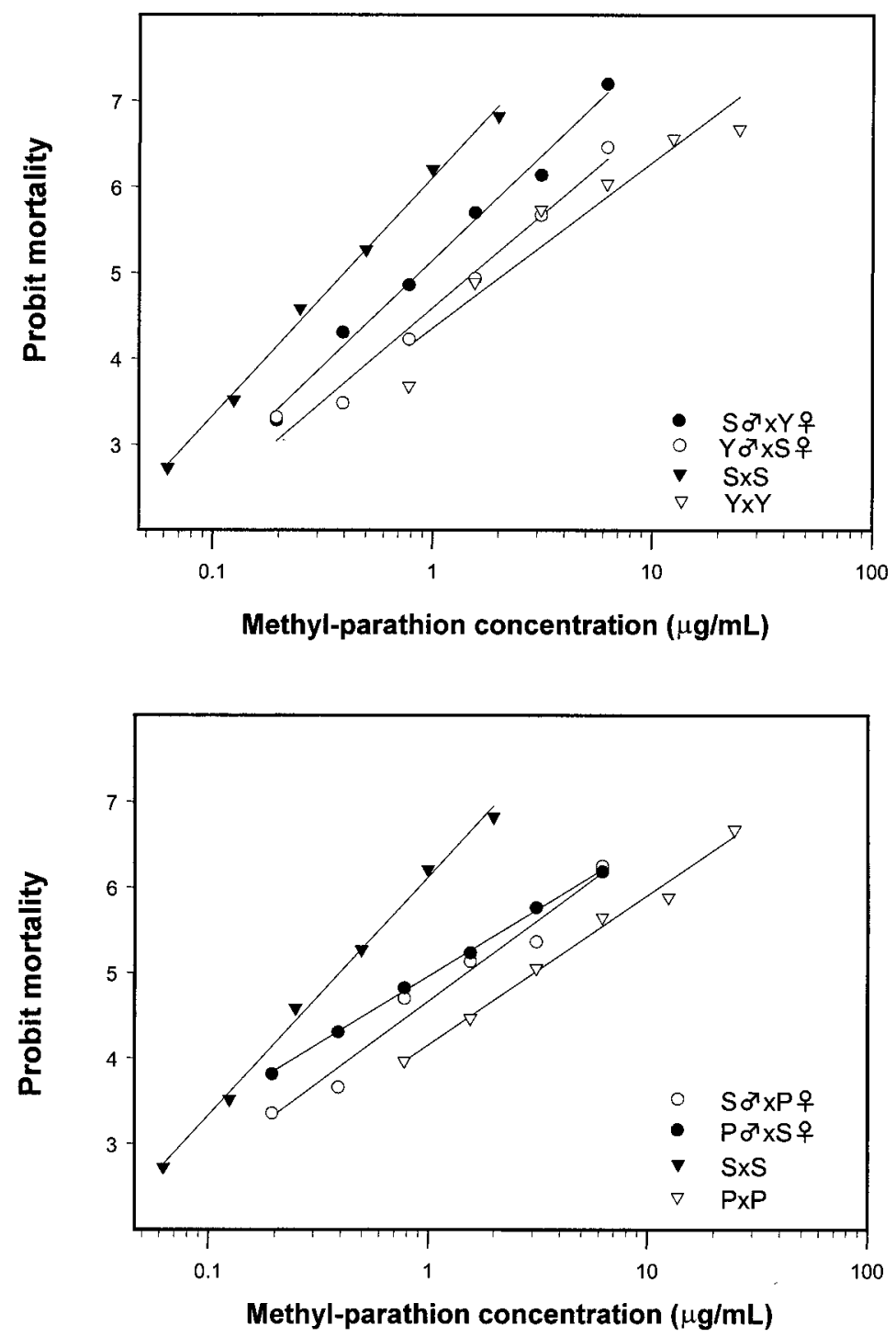

Fig. 1. Log(dose)- probit mortality plots (data pooled over 1998 and 1999) of methyl-parathion toxicity as determined by lethal concentration bioassays from 1998 and 1999 for the insecticide resistant corn rootworm populations (Y-York County and P-Phelps County) and the susceptible population (S-Saunders County) and their reciprocal crosses. Lines represent probit-transformed results of percent mortalities at different concentrations of methyl-parathion (shown as individual points).

lower than the susceptible population indicating a higher degree of heterogeneity in response to methylparathion. The degrees of dominance calculated for the reciprocal crosses (Table 1) suggest at least an intermediate to incompletely dominant form of resistance in both populations. However, the reciprocal crosses of the York $\times$ Saunders populations were significantly different from one another; i.e., the degrees of dominance were 0.73 and 0.04 for York $\times$ Saunders and the Saunders $\times$ York crosses, respectively. These results suggest the involvement of a sex-linked factor associated with the male-determining chromosome.

Inheritance of Enhanced Esterase Activity. Results of native PAGE and visualization of nonspecific es- terases revealed elevated group II esterase banding patterns associated with the two resistant parental populations and $F_{1}$ progeny of the four reciprocal crosses (Fig. 2). The intensity of esterase bands was similar among the parental resistant populations and the $\mathrm{F}_{1}$ progeny (Fig. 2), and the percentage of individuals assayed that exhibited elevated Group II esterases was not different (Table 2). Approximately $97 \%$ of the individuals from the resistant parental strains and the $\mathrm{F}_{1}$ progeny, and only $1 \%$ of the susceptible individuals produced intense banding with native PAGE. These results suggest that resistanceassociated esterases are inherited in a completely dominant manner. 
Table 1. Probit analysis (data pooled over 1998 and 1999) of methyl-parathion bioassay from insecticide resistant and susceptible western corn rootworm populations and their reciprocal crosses

\begin{tabular}{|c|c|c|c|c|c|c|c|c|}
\hline Population & $n^{a}$ & $\chi^{2 b}$ & Slope $( \pm \mathrm{SE})$ & $\begin{array}{c}\mathrm{LC}_{50} \\
(95 \% \mathrm{CI})^{c}\end{array}$ & $\mathrm{RR}_{50}{ }^{d}$ & $\begin{array}{c}\mathrm{LC}_{90} \\
(95 \% \mathrm{CI})^{c}\end{array}$ & $\mathrm{RR}_{90}{ }^{d}$ & $\begin{array}{l}\text { Degree of } \\
\text { dominance }\end{array}$ \\
\hline Saunders (S) & 600 & 1.58 & $2.77(0.20)$ & $0.39(0.35-0.44)$ & - & $1.13(0.95-1.40)$ & - & - \\
\hline York (Y) & 582 & $20.3^{*}$ & $2.05(0.16)$ & $2.04(0.99-3.32)$ & 5.23 & $8.58(4.93-31.0)$ & 7.59 & - \\
\hline Phelps (P) & 553 & 1.94 & $1.72(0.15)$ & $3.06(2.55-3.64)$ & 7.85 & $17.1(13.1-24.4)$ & 15.1 & - \\
\hline $\mathrm{Sot} \times \mathrm{Y}$ ㅇ & 466 & 3.22 & $2.32(0.19)$ & $0.88(0.75-1.02)$ & 2.26 & $3.12(2.52-4.11)$ & 2.76 & -0.037 \\
\hline $\mathrm{Y} \hat{0} \times \mathrm{S}$ 웅 & 724 & $5.34 *$ & $2.26(0.15)$ & $1.60(1.31-1.98)$ & 4.10 & $5.91(4.35-9.14)$ & 5.23 & 0.727 \\
\hline $\mathrm{S} \hat{0} \times \mathrm{P} q$ & 669 & $9.35^{*}$ & $1.85(0.13)$ & $1.51(1.09-2.13)$ & 3.87 & $7.44(4.54-17.5)$ & 6.58 & 0.301 \\
\hline $\mathrm{P} \hat{\sigma} \times \mathrm{S} q$ & 738 & 0.21 & $1.57(0.12)$ & $1.01(0.92-1.26)$ & 2.59 & $7.00(5.30-10.0)$ & 6.20 & -0.014 \\
\hline
\end{tabular}

${ }^{a}$ Number of insects used in each probit analysis.

${ }^{b}$ Chi-square goodness-of-fit as determined using POLO-PC and (*) departures from an expected model based on heterogeneity factor $\geq 1.0$.

${ }^{c}$ Lethal concentrations (in $\mu \mathrm{g} / \mathrm{ml}$ ) with $95 \%$ confidence intervals $(\mathrm{CIs})$ at the $50 \%\left(\mathrm{LC}_{50}\right)$ and $90 \%\left(\mathrm{LC}_{90}\right)$ levels of probit mortality.

${ }^{d}$ Resistance ratios indicate the fold-difference when compared with susceptible Saunders County population at $\mathrm{LC}_{50}$ and $\mathrm{LC}_{90}$.

Significantly higher esterase activity (i.e., hydrolysis of $p$-nitrophenyl acetate) from individual rootworm adults was observed in both resistant populations as well as in the $F_{1}$ reciprocal crosses of resistant and susceptible populations $(F=4.65, \mathrm{df}=6, P<0.01)$ (Table 2) relative to the susceptible Saunders population. The Phelps and York populations showed 6.6and 5.7-fold higher activity, respectively, than the sus-
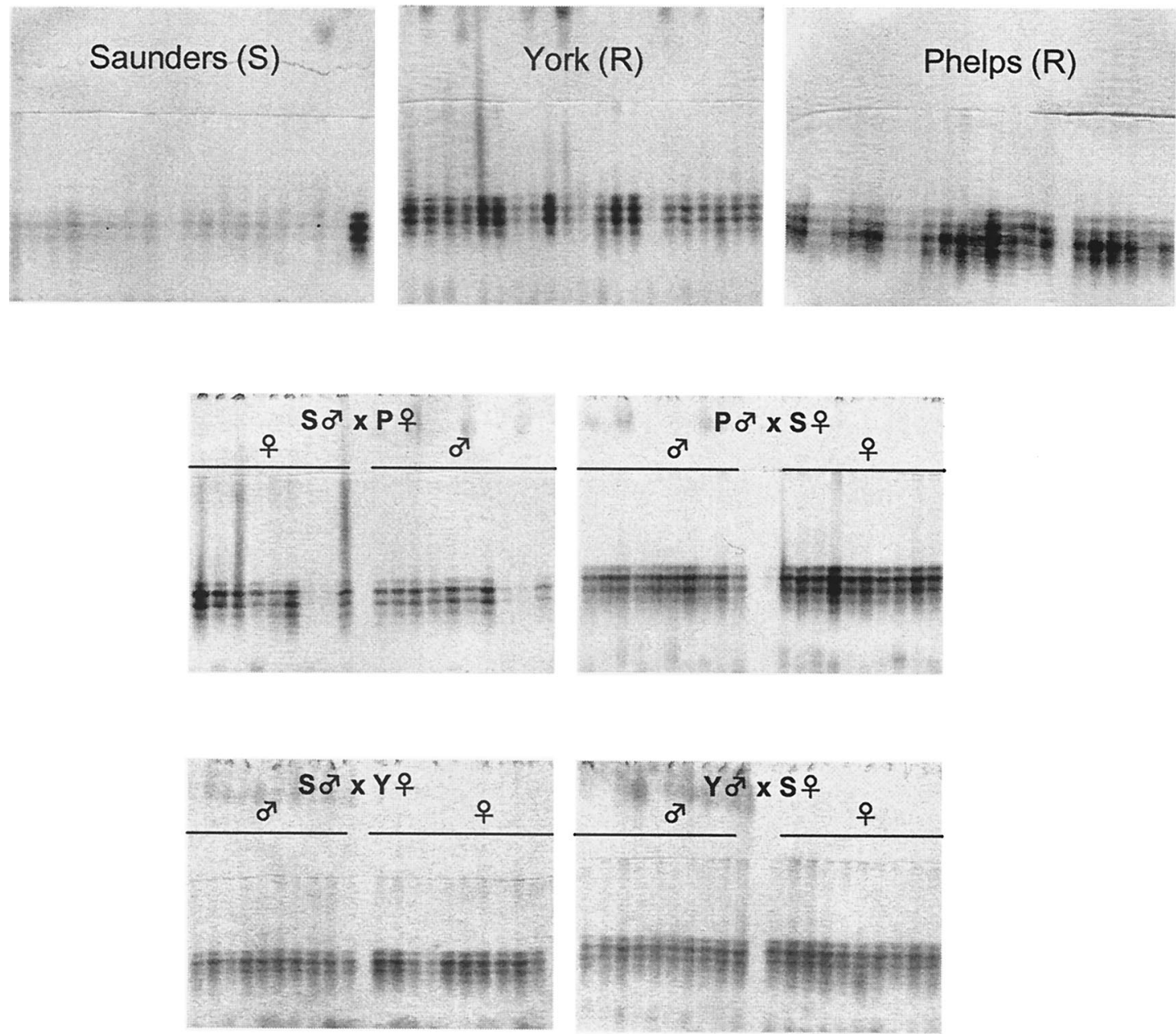

Fig. 2. Native PAGE of individual rootworm abdominal homogenates showing esterase banding patterns for susceptible (S, Saunders County) and resistant (P, Phelps County and Y, York County) western corn rootworm populations and their reciprocal crosses from 1999. 
Table 2. Nonspecific esterase activity of insecticide resistant (York and Phelps) and susceptible (Saunders) western corn rootworm populations and their reciprocal crosses

\begin{tabular}{|c|c|c|}
\hline Population & $\begin{array}{c}\text { Percentage } \\
\text { group II esterases }{ }^{a}\end{array}$ & $\begin{array}{c}\mathrm{PNPA}^{b, c} \\
(\mathrm{nmol} / \mathrm{min} / \text { rootworm })\end{array}$ \\
\hline Saunders (S) & 1.04 & $113.76 \pm 16.25 \mathrm{~d}$ \\
\hline York (Y) & 97.92 & $650.58 \pm 23.89 \mathrm{ab}$ \\
\hline Phelps (P) & 96.88 & $747.04 \pm 31.92 \mathrm{a}$ \\
\hline $\mathrm{S} \delta \times \mathrm{Y}$ ㅇ & 94.79 & $511.11 \pm 12.84 \mathrm{bc}$ \\
\hline $\mathrm{Y} \delta \times \mathrm{S} q$ & 98.96 & $573.21 \pm 16.20 \mathrm{abc}$ \\
\hline $\mathrm{S} \sigma \overrightarrow{\mathrm{P}}+$ & 96.88 & $650.11 \pm 17.00 \mathrm{ab}$ \\
\hline $\mathrm{P} \delta \times \mathrm{S}$ 우 & 97.92 & $638.84 \pm 23.77 \mathrm{ab}$ \\
\hline
\end{tabular}

${ }^{a}$ Percent individuals exhibiting elevated group II esterases calculated from a total of 96 individuals used in native PAGE.

${ }^{b}$ PNPA, $p$-nitrophenyl acetate.

${ }^{c}$ Results are means $\pm \mathrm{SE}$ of 96 individuals with two replicate determinations. Letters followed by same letter are not significantly different by the Fisher's least significant difference test $(P \leq 0.05)$.

ceptible Saunders population. Esterase activity of individual rootworm abdomens from the $F_{1}$ progeny of reciprocal crosses was also significantly higher than the Saunders population, but was not significantly different from either resistant parental population. These results are consistent with results from native PAGE and support the pattern of complete dominance observed with elevated resistance-associated esterases.

\section{Discussion}

The results of this investigation indicate that western corn rootworm resistance to methyl-parathion and elevated esterase activity that is associated with resistance are inherited differently. Specifically, bioassays of reciprocal crosses for two resistant populations suggest that inheritance of the resistance was intermediate, while the activity of nonspecific esterases (measured by both native PAGE and activity assays) suggests a dominant pattern of inheritance. Furthermore, in the resistant York population, the level of resistance observed in the two reciprocal crosses was significantly different indicating that the resistance is at least partially sex-linked. In reciprocal crosses of the resistant Phelps population, the progeny responded similarly, suggesting an autosomal location of the resistance gene(s). Resistance was also found to be incompletely dominant and autosomal to azinphosmethyl in Colorado potato beetle, Leptinotarsa decemlineata (Say) (Argentine et al. 1989) and malathion in red flour beetle, Tribolium castaneum (Herbst) (White and Bell 1988). In contrast to bioassay results, the pattern of esterase isozyme staining on native PAGE gels, as well as esterase activity, were not significantly different among reciprocal crosses or between resistant parental populations indicating autosomal and dominant inheritance.

The differences observed between the inheritance of resistance and elevated esterase activities suggest that resistance factors other than enhanced hydrolytic metabolism are involved in these populations. Previous research on these same populations has demon- strated an involvement of both hydrolytic and oxidative (cytochrome P450s) metabolism in the resistance (Miota et al. 1998, Scharf et al. 1999, 2001). Involvement of such additional resistance factors could explain the differences between the inheritance of resistance and the observed esterase characteristics, if the additional factor (i.e., elevated oxidative metabolism) was inherited as a recessive trait. We initially focused on esterases because of the potential for developing esterase-based biochemical markers that would be diagnostic for insecticide resistance. Limited availability of $F_{1}$ progeny from the reciprocal crosses precluded our assessment of P450-dependent activities that would have provided additional information about the inheritance patterns observed.

It should also be noted that the parental populations used to establish the reciprocal crosses were probably not isogenic for resistance. If the resistant parental populations contained individuals that possessed a susceptible genotype, it is likely that some of the $F_{1}$ progeny would be susceptible homozygotes, and assessment of dose-response would have been confounded by the mixed genotype. Such contamination of the $F_{1}$ progeny might account for the sex-linked inheritance associated with one strain and not the other.

Although the results of this investigation are inconclusive with regard to the precise nature of resistance inheritance, they do provide insight into the potential for developing simple, diagnostic assays to assess resistance allele frequency. In the case of diagnostic bioassays, the low resistance levels (5-7-fold) and the apparent intermediate inheritance makes the determination of insecticide concentrations that discriminate among genotypes difficult at best. Even biochemical approaches that directly assess activity of the esterase isozymes among individual beetles would not discriminate between heterozygotes and homozygotes. Therefore, a molecular approach that readily identifies specific mutations or changes in gene expression will be necessary for assessment of allele frequency.

Based on the inheritance studies described in this investigation, we can begin to generate information on specific genetic factors that dictate the evolutionary divergence of discrete resistant populations (Meinke et al. 1998) and facilitate modeling efforts designed to approximate the movement of resistant genes among populations. This information will be useful for development of resistance management recommendations for new technologies, such as transgenic plants.

\section{Acknowledgments}

Our appreciation is extended to Jim Brown and Kathryn Sterling for their assistance in beetle rearing and native PAGE. We also appreciate the manuscript review by Drs. Gary Hein and Tim Nowatzki. Partial funding for this project was provided by USDA-ARS specific cooperative agreement 58-5447-6-116 and the USDA Initiative for Future Agricultural and Food Science (Grant \#00-52103-9699). This is journal series No. 13709 of the University of Nebraska Ag- 
ricultural Research Division and contribution No. 1126 of the Department of Entomology.

\section{References Cited}

Argentine, J. A., J. Marshall Clark, and D. N. Ferro. 1989. Genetics and synergism of resistance to azinphosmethyl and permethrin in the Colorado potato beetle (Coleoptera: Chrysomelidae). J. Econ. Entomol. 82: 698-705.

Boetel, M. A., and B. W. Fuller. 1997. Seasonal emergencetime effects on adult longevity, fecundity, and egg viability of Northern and Western corn rootworms (Coleoptera: Chrysomelidae). J. Econ. Entomol. 26: $1208-$ 1212

Dittrich, V. 1972. Phenotypic expression of gene $\mathrm{OP}^{\mathrm{L}}$ for resistance in twospotted spider mites tested with various organophosphates. J. Econ. Entomol. 65: 1248-1255.

Finney, D. J. 1971. Probit analysis. Cambridge University Press, Cambridge, UK.

Godfrey, L. D., L. J. Meinke, and R. J. Wright. 1993. Vegetative and reproductive biomass accumulation in field corn: response to root injury by western corn rootworm (Coleoptera: Chrysomelidae). J. Econ. Entomol. 86: $1557-1573$

Gray, M. E., and K. L. Steffey. 1998. Corn rootworm (Coleoptera: Chrysomelidae) larval injury and root compensation of 12 maize hybrids: an assessment of the economic injury index. J. Econ. Entomol. 91: 723-740.

Hou, X., L. J. Meinke, and T. J. Arkebauer. 1997. Soil moisture and larval western corn rootworm injury: influence on gas exchange parameters. Agron. J. 89: 709-717.

LeOra Software. 1987. POLO-PC. A user's guide to probit analysis or logit analysis. LeOra Software, Berkeley, CA.

Mayo, Z. B., and L. L. Peters. 1978. Planting vs. cultivation time applications of granular soil insecticides to control larvae of corn rootworm in Nebraska. J. Econ. Entomol. 71: 801-803

Meinke, L. J. 1995. Adult corn rootworm management Univ. Nebr. Agric. Res. Div. Misc. Publ. 63.

Meinke, L. J., B. D. Siegfried, R. J. Wright, and L. D. Chandler. 1998. Adult susceptibility of Nebraska western corn rootworm (Coleoptera: Chrysomelidae) populations to selected insecticides. J. Econ. Entomol. 91: $594-600$.

Miota, F., M. E. Scharf, M. Ono, P. Marćon, L. J. Meinke, R. J. Wright, L. D. Chandler, and B. D. Siegfried. 1998. Mechanisms of methyl and ethyl parathion resistance in the western corn rootworm (Coleoptera: Chrysomelidae). Pest. Biochem. Physiol. 61: 39-52.

Reidell, W. E. 1990. Rootworm and mechanical damage effects on root morphology and water relations in maize. Crop Sci. 30: 628-631.
Pruess, K. P., J. F. Witkowski, and E. S. Raun. 1974. Population suppression of western corn rootworm by adult control with ULV Malathion. J. Econ. Entomol. 67: 541545.

Savin, N. E., J. L. Robertson, and R. M. Russell. 1977. A critical evaluation of bioassays in insecticide research: likelihood ratio tests of dose-mortality regression. Bull. Entomol. Soc. Am. 23: 257-266.

SAS Institute. 2001. SAS/STAT user's guide, SAS Institute, Cary, NC.

Scharf, M. E., L. J. Meinke, B. D. Siegfried, R. J. Wright, and L. D. Chandler. 1999. Carbaryl susceptibility, diagnostic concentration determination, and synergism for U. S. populations of western corn rootworm (Coleoptera: Chrysomelidae). J. Econ. Entomol. 92: 33-39.

Scharf, M. E., S. Parimi., L. J. Meinke, L. D. Chandler., and B. D. Siegfried. 2001. Expression and induction of three family 4 cytochrome P450 (CYP4)* genes identified from insecticide-resistant and susceptible western corn rootworms, Diabrotica virgifera virgifera. Insect Mol. Biol. 10: 139-146.

Spike, B. P., and J. J. Tollefson. 1991. Yield response of corn subjected to western corn rootworm (Coleoptera: Chrysomelidae) infestation and lodging. J. Econ. Entomol. 84: $1585-1590$.

Stone, B. S. 1968. A formula for determining degree of dominance in cases of monofactorial inheritance of resistance to chemicals. Bull. W.H.O. 38: 325-326.

Sutter, G. R., J. R. Fischer, N. C. Elliott, and T. F. Branson. 1990. Effect of insecticide treatments on root lodging and yields of maize in controlled infestations of western corn rootworm (Coleoptera: Chrysomelidae). J. Econ. Entomol. 83: 2414-2420.

Urías-López, M. A., and L. J. Meinke. 2001. Influence of western corn rootworm (Coleoptera: Chrysomelidae) larval injury on yield of different types of maize. J. Econ. Entomol. 94: 106-111.

White, N.D.G., and R. J. Bell. 1988. Inheritance of malathion resistance in a strain of Tribolium castaneum (Coleoptera: Tenebrionidae) and effects of resistance genotypes on fecundity and larval survival in malathiontreated wheat. J. Econ. Entomol. 81: 381-386.

Zhou, X., M. E. Scharf, S. Parimi, L. J. Meinke, R. J. Wright, L. D. Chandler, and B. D. Siegfried. 2002. Biochemical diagnostic assays of western corn rootworm (Coleoptera: Chrysomelidae) based on esterase-mediated resistance mechanisms. J. Econ. Entomol. 95: 1261-1266.

Received for publication 6 May 2002; accepted 20 September 2002 